EPISTEME KOINONIA

Revista Electrónica de Ciencias de la Educación, Humanidades, Artes y Bellas Artes
Año II. Vol II. N³.
Enero - Junio, 2019
Hecho el depósito de Ley: FA2018000022
ISSN: 2665-0282
FUNDACIÓN KOINONIA (F.K).
Santa Ana de Coro, Venezuela
Carely Bello

http://dx.doi.org/10.35381/e.k.v2i3.517

\title{
Comunicación efectiva desde la gerencia educativa
}

\section{Effective communication from educational management}

\author{
Carely Bello \\ carely bello@hotmail.com \\ Centro de Educación Inicial San José, Santa Ana de Coro \\ Venezuela
}

Recibido: 15 de octubre de 2018

Aprobado: 15 de noviembre de 2018

\section{RESUMEN}

La investigación tuvo por objetivo general analizar la comunicación efectiva desde la gerencia educativa del Centro de Educación Inicial San José del municipio Miranda, Coro - Estado Falcón, Venezuela, metodológicamente fue de tipo descriptiva, La población estuvo representada por el personal del CEI San José, para un total de 16 docentes, de acuerdo con los datos suministrados por la dirección de dicha institución, se empleó la técnica de la encuesta y el cuestionario en escalamiento tipo Likert de cinco alternativas de respuestas, Siempre (5), Casi siempre (4), Algunas veces (3), Casi Nunca (2), Nunca (1), el cual obtuvo un coeficiente de Alfa de Cronbach de 0,91 lo cual lo cataloga como un instrumento altamente confiable de aplicar. En cuanto a la comunicación efectiva, la sumatoria de las alternativas negativas suman un $63 \%$. El gerente debe trasmitir mensajes claros y precisos para evitar distorsiones en el mensaje y conflictos.

Descriptores: comunicación interactiva; comunicación interpersonal; comunicación en grupo; relaciones entre grupos.

\begin{abstract}
The general objective of the research was to analyze the effective communication from the educational management of the San José Initial Education Center of the Miranda municipality, Coro - Falcón State, Venezuela, methodologically it was descriptive, the population was represented by the staff of the CEI San José, for a total of 16 teachers, according to the data provided by the management of said institution, the survey technique and the Likert-type scaling questionnaire of five response alternatives were used, Always (5), Almost always (4), Sometimes (3), Almost Never (2), Never (1), which obtained a Cronbach's alpha coefficient of 0.91 which lists it as a highly reliable
\end{abstract}




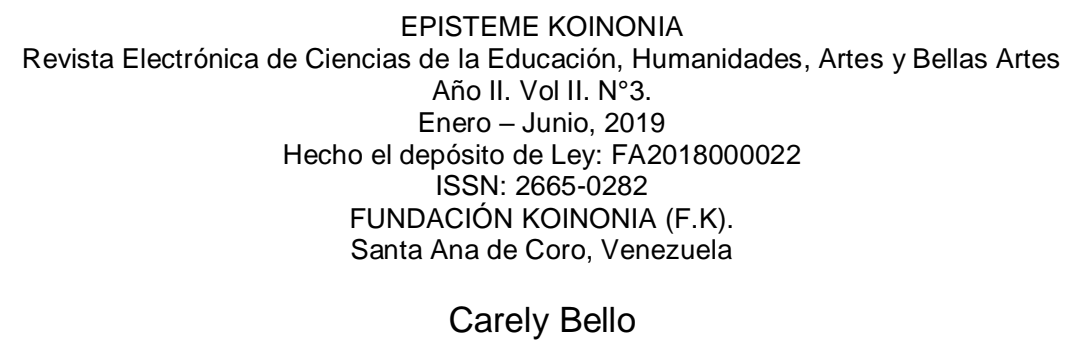

instrument to apply. As for effective communication, the sum of negative alternatives adds up to $63 \%$. The manager must transmit clear and precise messages to avoid distortions in the message and conflicts.

Descriptors: interactive communication; Interpersonal communication; Group communication; Intergroup relations.

\section{INTRODUCCIÓN}

La comunicación permite transmitir información, intercambiar emociones, expresar sentimientos y opiniones, establecer ideales, de manera escrita, oral o gestual, todo el cuerpo se comunica a través de las diversas formas humanas. Como personas sociales, la comunicación es parte de cada uno de los aspectos de la vida, incluso de aquellos referidos a los espacios laborales y/o organizacionales, siendo tan importante como en el resto de las esferas donde se convive, sin embargo, sea cual sea el escenario, la comunicación debe caracterizarse por ser armónica, flexible, efectiva y asertiva, pues de ella dependen numerosas acciones, proyectos, consecución de metas, vinculaciones afectivas, entre otras; la comunicación no efectiva genera conflictos y puntos críticos en las relaciones interpersonales, que afectan no solo la vida social sino además a la organización.

Desde la perspectiva de la escuela, como organización social, la comunicación es un aspecto de suma relevancia, al respecto Morán (2008) señala que: "el docente transmite, con sus relaciones interpersonales una serie de valores, como el respeto mutuo, el diálogo, la comprensión, el apoyo y el afecto" (p. 23). La comunicación permite ayudar a otros, ser responsables, tolerantes, éticos y honestos, conseguir relaciones interpersonales armónicas gracias a una comunicación efectiva, genera en todo el colectivo institucional un ambiente escolar placido, motivador y propicia el desarrollo personal social de cada uno de los miembros de la escuela. A tal efecto, Cava y Gonzalo (2007) indican que: 


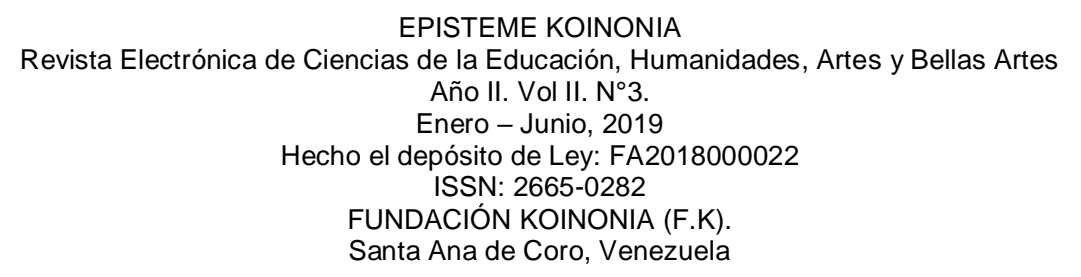

Carely Bello

El contacto recíproco y la comunicación son esenciales tanto para el individuo como para el grupo, de tal manera que sin ellos, la persona perecería y el grupo dejaría de funcionar. Esto es lo que se conoce como relaciones interpersonales (p. 12).

En otro orden de ideas, la comunicación es necesaria para el desarrollo de las relaciones interpersonales. Arias y Heredia, (2009), las definen como la "interacción entre dos o más personas" (p. 371). La diferencia entre el hombre y el animal es su sentido del lenguaje, su capacidad de comunicarse, de allí la importancia que tiene para las relaciones con los otros, la interacción permanente entre todos; una buena relación comunicativa implica una vida física y mental más sana, en completa armonía con la sociedad.

En este sentido, la comunicación es uno de los aspectos fundamentales dentro de una organización, en especial de índole educativo, pues su efectiva permite lograr la armonía entre sus miembros proporcionando un clima organizacional agradable y una toma de decisiones asertivas, lo que Maldonado (2009), refiere: "la comunicación es un proceso que los seres humanos llevamos a cabo para transmitir nuevas ideas, pensamientos o conocimientos sin embargo no es fácil llevarla a cabo, y si esta se realiza de manera deficiente genera conflictos interpersonales" (p. 9).

La comunicación, desde una vertiente psicológica esta implica en las actitudes, personalidad, interacciones sociales y relaciones interpersonales de allí que su relación con la toma de decisiones y el clima organizacional es evidente desde el mismo momento en que implica una gama de emociones y sentimientos que se generan a partir de las relaciones que surgen de esa interacción organizativa. A través de una comunicación efectiva el trabajo en equipo fluye, la toma de decisiones es participativa y el ambiente laboral es armónico.

De allí que para, Hernández (2007), expresa que: "la comunicación efectiva es aquella que al ser aplicada y desplegada en la escuela coadyuva al logro de las metas y objetivos de la organización escolar" (p. 6). Por lo tanto, la comunicación efectiva es 


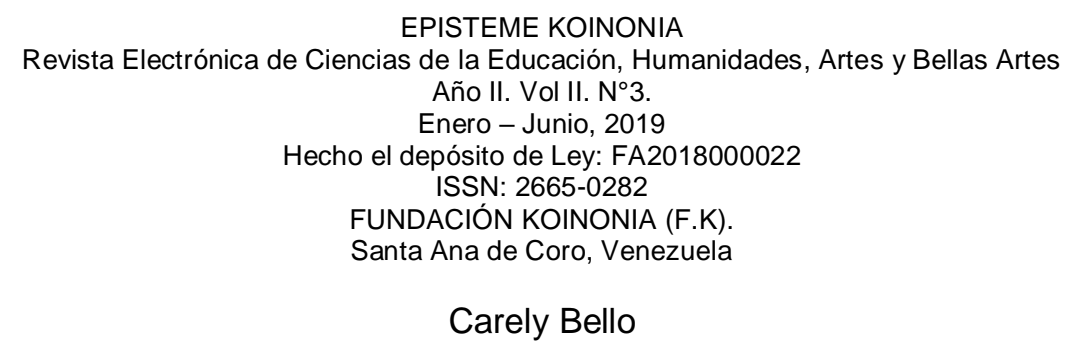

necesaria desde la escuela como organización social, pues existen diferentes tipos de comunicación desde estos espacios educativos, entre ellas: las del personal en sí, y la de estos con el director, así como las del personal con los padres y representantes, y con la comunidad en general. La comunicación efectiva debe promoverse desde la gerencia para que la interacción sea fluida, clara y precisa y llegar a acuerdos sobre como coordinar las acciones y darle solución a los diversos problemas que se presentan, contribuye con una toma de decisiones asertiva.

Asimismo, Robbin (2009), señala: "para ser comunicadores efectivos los directores tienen que comprender no solo los conceptos generales de la comunicación dentro de las organizaciones, no es solo dar órdenes mostrando una imagen autoritaria y actitudes descalificativas del trabajo del resto del personal" (p. 12). Igualmente, Peña (2010) manifiesta que: "la actuación de los directores de las escuelas Primaria no se corresponde con los principios y funciones de la gerencia educativa" (p. 18), esta afirmación se debe a la subjetividad con la cual se está manejando la gerencia, porque los procesos de comunicación, toma de decisiones, resolución de conflictos y la eficacia de las relaciones interpersonales no van en beneficio ni de la organización ni de cada uno de sus miembros, perjudicando el rendimiento y el desempeño del personal.

Cabe destacar que, el director como gerente educativo debe manejar la comunicación con fluidez, objetividad y efectividad para que el personal actué en virtud de las metas de la institución educativa en una armonía y producción positiva, y en la cual la importancia de las relaciones interpersonales sean espacios de respeto, cooperación, participación, pertinencia y compromiso. Del mismo modo, el gerente debe asumir un rol estratégico para buscar alternativas que mejoren la calidad personal, profesional e institucional de su escuela y los miembros.

De acuerdo a la investigación auspiciada por la UNESCO (2007) donde concluyen que el proceso comunicativo en las escuelas de Puerto Rico esta decadente de valores sociales que afectan negativamente las relaciones interpersonales entre el personal 


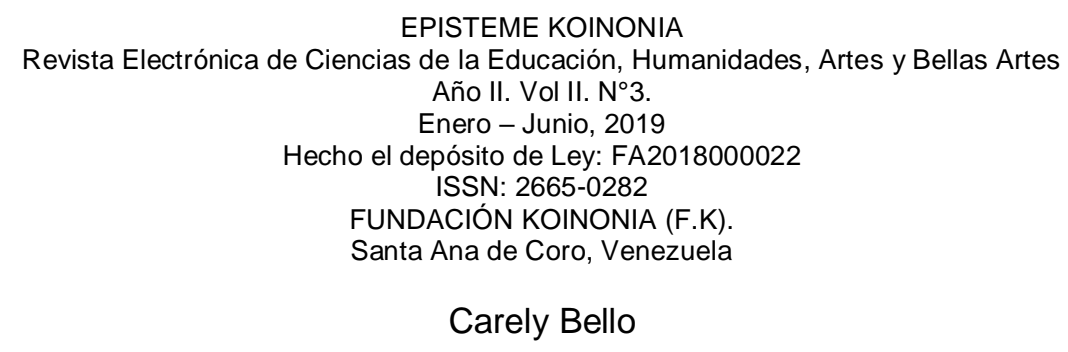

directivo y docente, lo cual ejerce una influencia importante en las ejecutorias de los estudiantes en ese país, más allá de los factores socioeconómicos.

Por su parte, en Venezuela también se registran situaciones similares, tal y como lo indica Medina, (2010), quien señala que en las instituciones escolares del país son muy marcadas las diferencias personales que se suscitan entre los diversos miembros del personal, quienes frecuentemente deterioran el proceso comunicativo efectivo con acciones carentes de valores como respeto, solidaridad, cooperación y tolerancia.

El proceso de comunicación debe ser efectivo para que la escuela logre los propósitos y metas organizacionales, su personal debe saber comunicarse siendo el gerente el mayor garante de que la comunicación sea la adecuada entre su personal, más aun entre él y su colectivo institucional. Ante estos planteamientos, cabe destacar que el CEI San José, ubicado en el sector San José de la parroquia San Gabriel del municipio Miranda, estado Falcón, no escapa a ésta realidad ya que se pudo observar que dentro de la institución existen diversas situaciones que ponen de manifiesto la existencia de una marcada problemática en el proceso de comunicación efectiva entre el personal directivo y docente.

En este sentido, las características de esta problemática, se mencionan: el director solo se dirige al personal cuando necesita que conozcan los lineamientos e instrucciones del trabajo a realizar, actitud pasiva y desinteresada del director en propiciar procesos comunicativos armónicos, el maltrato verbal por parte de los gerentes educativos, la falta de comunicación permanente y eficiente entre el personal que labora en dicha institución; fallas comunicacionales que repercuten en la lentitud de los procesos administrativos y docentes, relaciones interpersonales deterioradas, información de pasillo que no dan objetividad al proceso gerencial ni educativo, conflictos permanentes entre el personal y el director, la actuación y desempeño del director no es motivador, no se genera en la institución un espacio de formación, respeto, creatividad, un clima de paz laboral y armonía en la institución. 


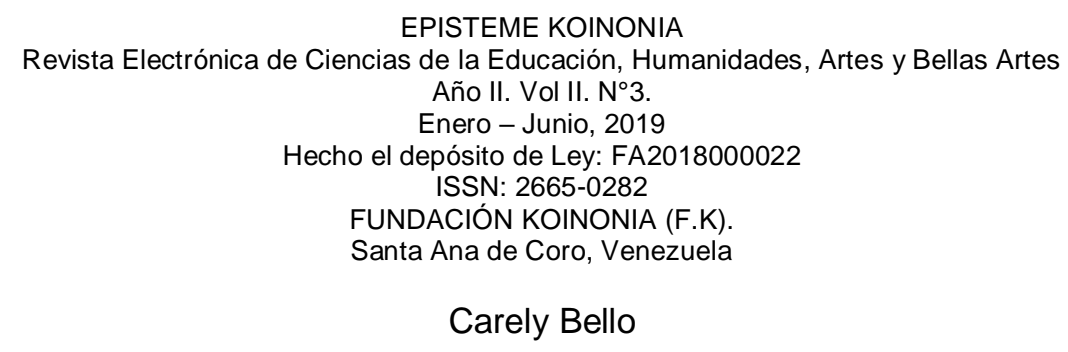

En este sentido, además la ineficiencia en el trabajo, falta de cooperación entre compañeras para la ejecución de las labores educativas, así como inapropiado clima laboral para compartir tiempo, espacios, logros, proyectos y expectativa de grupo, frecuentes situaciones conflictivas entre docentes y la apatía por participar activamente en la resolución de conflictos, desgaste emocional de las docentes, el cual puede afectar el equilibrio emocional de las mismas en ciertos momentos, reflejándose en su salud psicológica, el comportamiento humano, la ética de las docentes, y el desinterés por la motivación al logro.

En tal sentido, y tomando en consideración la realidad de lo planteado, en esta investigación se destaca la importancia del rol estratégico del gerente en la comunicación efectiva entre el colectivo institucional del CEIB San José, considerando la comunicación de forma efectiva y eficiente, a través de la cual se pueden generar actitudes positivas en cada persona que participa en ella, logrando un bienestar personal y social hacia la excelencia y calidad de vida personal, todo ello bajo una atmosfera de optimas relaciones interpersonales, buscando a través de ellas la excelencia en el liderazgo, alto desempeño y motivación del personal. Por consiguiente la investigación tuvo por objetivo general: Analizar la comunicación efectiva desde la gerencia educativa del Centro de Educación Inicial San José del municipio Miranda, Coro - Estado Falcón, Venezuela.

\section{REFERENCIAL TEÓRICO}

\section{Comunicación Efectiva}

La comunicación puede darse de manera formal, la que da entre la organización y fluye a través de los canales organizaciones con un contenido específico para ella, y de manera informal la que surge entre diversos grupos de la organización, con canales poco formales y un aspecto relevante de esta es la influencia que tiene en la comunicación formal. Para Munich y García (2000) la comunicación: "es el proceso a través del cual se transmite y recibe información en un grupo social” (p. 56). Según 


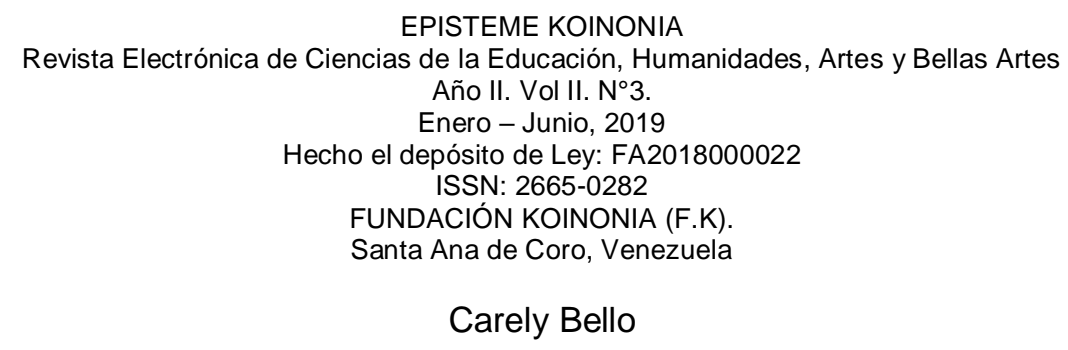

Robbins (2004) señala: "ningún grupo puede existir sin la comunicación: ésta es la transmisión de significados entre sus miembros. Sólo mediante la transmisión de significados de una persona a otra se puede compartir información e ideas" (p. 376). En este sentido, la comunicación permite el entendimiento entre las personas, porque busca coordinar las actividades y ponerse de acero, para el éxito comunicativo no solo se le da valor a la transmisión, sino además a ese entendimiento entre receptores y emisores que le permite apreciar el verdadero significado de lo que se quiere comunicar.

Del mismo modo, para Davis y Newstrom (2003), definen la comunicación como: "una transferencia de información y comprensión entre dos o más personas, considerándola como un puente entre los hombres, permitiéndole compartir los sentimientos y conocimientos adquiridos, siendo útil a la gerencia" (p. 82), la comunicación es un proceso donde se trasmite un mensaje esperando una respuesta o reacción. Para Robbins (1999), la comunicación requiere de un propósito (mensaje), una fuente (emisor), un receptor, un medio por donde transmitirlo (canal) y la traducción de ese mensaje para hacerlo entendible (decodificación), todo ello implica una transferencia de significados de una persona a otra.

Según Chiavenato (2000), el proceso comunicativo requiere de dos personas, la que envía el mensaje, y quien lo recibe, a lo que él considera que para que la comunicación sea efectiva deben existir los elementos básicos como son: emisor, transmisor, receptor y procedimiento. Para este autor, entre los elementos del proceso de comunicación, se encuentran: la fuente (sujeto que inicia el mensaje y lo codifica a través de cuatro condiciones: habilidad, actitud, conocimientos y sistema sociocultural), el canal (medio por donde viaja el mensaje, siendo formales e informales), el receptor (sujeto quien dirige el mensaje) y la retroalimentación (verificación del mensaje evitando malos entendidos).

Así mismo Chiavenato (2000) señala que la comunicación deja de ser efectiva entre las personas cuando estas preponderan sus valores e ideales ante el mensaje recibido, el 


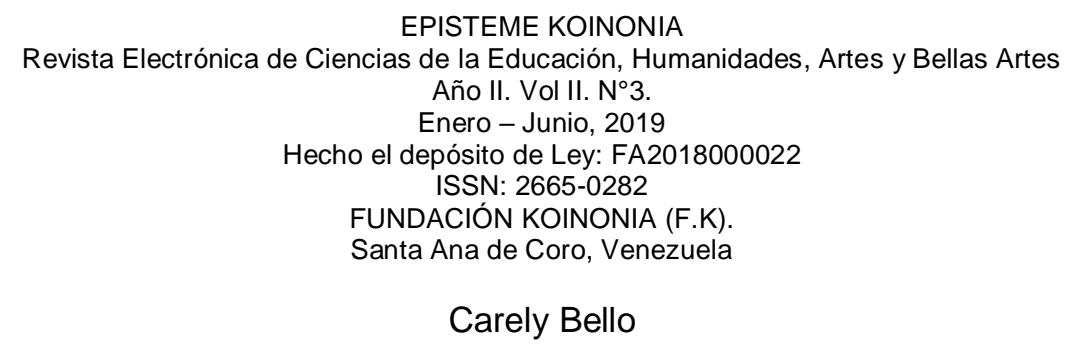

cual interpreta según estos elementos, y allí se complica el mensaje original que se quiere dar, estos elementos son como filtros donde las personas seleccionan y rechazan la información que no es cónsona con sus intereses. La comunicación puede ser de dos tipos: descendente cuando fluye de manera directa desde los niveles superiores a los inferiores (jerarquía organizativa), y ascendente, donde se crea un ambiente empático para dar buenas y malas noticias, este es el propio ambiente que el gerente debe propiciar para que la comunicación sea solida entre todos, de esta forma el gerente está en permanente sintonía con sus empleados y le proporciona información importante para la toma de decisiones. Del mismo modo, autores como Robbins (1999) consideran que la comunicación es lateral u horizontal, esta se desarrolla entre los miembros de un mismo nivel de la jerarquía, permite la integración y coordinación, además del apoyo emotivo y social.

\section{Comunicación efectiva en gerentes educativos}

La comunicación es clave para las organizaciones, le permite al gerente alcanzar altos niveles de productividad y eficiencia, para Ceballos (2013) señala: "la comunicación es un proceso de trasmisión y recepción de mensaje, cuyos contenidos inciden en las tomas de decisiones y motivaciones laborales, por medio de ello se puede controlar los comportamientos organizacionales" (p. 265). La comunicación es un elemento importante en la gerencia de una institución, porque a través de ella se interactúa eficazmente con el personal que allí labora. Para Robbins y Coulter (2010), la comunicación es "la transferencia y la comprensión de significados"(p. 315), a través de ella se mejora la comprensión y la capacidad de transmitir sentimientos e ideas, así como lograr el entendimiento entre las personas.

De acuerdo con Daft y Marcic (2010), la comunicación " es el proceso por el cual se intercambian y entiende la información entre dos o más personas, por lo general con la intención de motivar o influir en el comportamiento" (p. 484), permite desde las interacciones más sencillas hasta las más complejas para consolidar las estrategias 


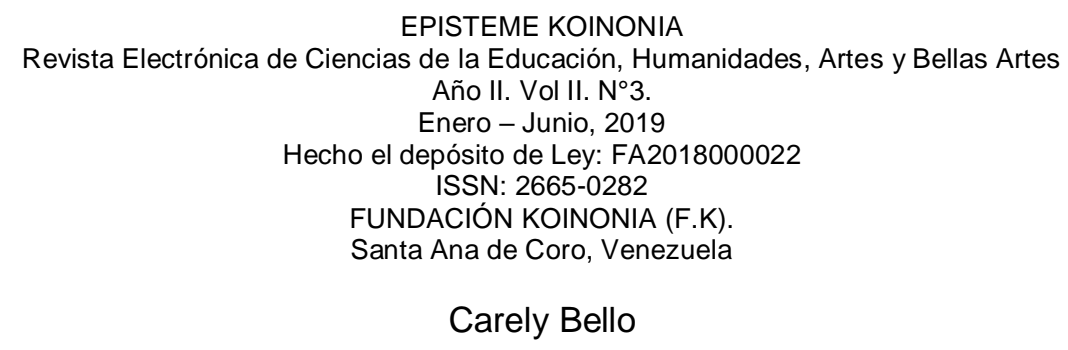

organizacionales, la comunicación es un aliado de la gerencia, su efectividad dependerá de la forma como se desarrolle. El gerente debe tener competencias para lograr que la comunicación sea efectiva, entre ellas: habilidades, conocimientos y capacidades para trasmitir la información, permitir la retroalimentación, escuchar activamente, ser empático, saber interpretar los mensajes, ser eficiente en la comunicación escrita, entre otros.

\section{Relaciones Interpersonales}

Según Bisquerra (2003), una relación interpersonal "es una interacción recíproca entre dos o más personas" (p. 421), para Fernández (2003), "trabajar en un ambiente laboral óptimo es sumamente importante para los empleados, ya que un entorno saludable incide directamente en el desempeño que estos tengan y su bienestar emocional" ( $p$. 256) Según estos autores, las relaciones interpersonales implican las interacciones diarias con otras personas, sean compañeros de trabajo, vecinos, amigos, entre otros. Cuando estas se ubican en el plano laboral, las relaciones interpersonales orientan cambios hacia los objetivos institucionales, estas relaciones se caracteriza por el respeto, la estima, la solidaridad, el compañerismo, el trabajo en equipo y la disposición de trabajar por un bien común. Del mismo modo, al igual que en el ámbito personal, pueden generar conflictos y barreras que perjudiquen de algún modo el buen clima organizacional, sin embargo, la ética y el profesionalismo debe obedecer más a los criterios personales que hayan de tener lugar.

En este sentido, las relaciones interpersonales pueden ser de diferentes tipos de acuerdo al nivel de vinculación entre las personas que la conforman, pueden ser básicas o profundas, e incluso intermedias, esto dependerá de la conexión e interacción entre las personas. El ser humano es el protagonista en las relaciones interpersonales tomando en cuenta algunas herramientas para facilitarlas como comunicación, confianza, empatía, pertenencia, entre otros. 


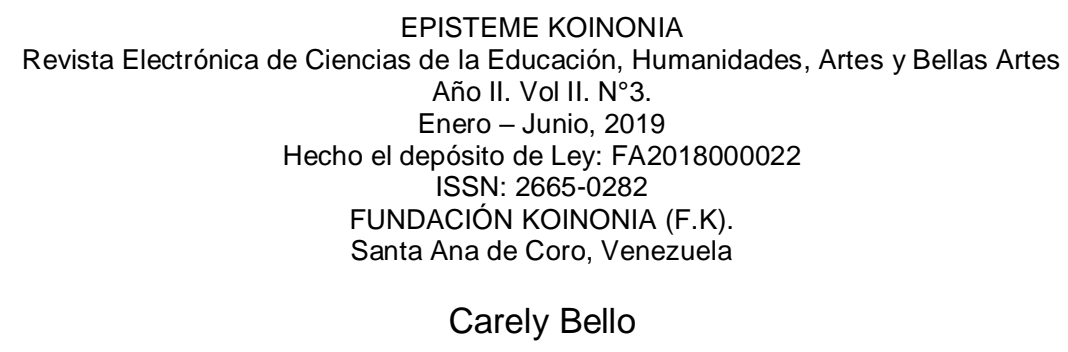

Por lo tanto, las relaciones interpersonales desde el campo educativo facilita las funciones de los miembros del colectivo institucional, son una herramienta de la organización para que interactúan de forma más amena y efectiva, ella desde la escuela van dirigidas hacia la comunicación, como un elemento que permite el intercambio de ideas, información, percepciones, principios con la finalidad de unificar criterios y tomar decisiones oportunas y eficientes.

\section{METODOLOGÍA DE LA INVESTIGACIÓN}

La investigación se basó en un nivel descriptivo, el cual Chávez (2010) considera que una "investigación descriptiva consiste en la caracterización de un hecho, fenómeno o grupo con el fin de establecer su estructura o comportamiento" (p. 46), generándose un análisis sobre la comunicación efectiva desde la gerencia educativa del Centro de Educación Inicial San José del municipio Miranda, Coro - Estado Falcón, Venezuela.

La población para esta investigación estuvo representada por el personal del CEI San José, para un total de 16 docentes, de acuerdo con los datos suministrados por la dirección de dicha institución, se empleó la técnica de la encuesta y el cuestionario en escalamiento tipo Likert de cinco alternativas de respuestas, Siempre (5), Casi siempre (4), Algunas veces (3), Casi Nunca (2), Nunca (1), el cual obtuvo un coeficiente de Alfa de Cronbach de 0,91 lo cual lo cataloga como un instrumento altamente confiable de aplicar, de ese modo, se obtuvieron datos que fueron procesados mediante la estadística descriptiva. 
EPISTEME KOINONIA

Revista Electrónica de Ciencias de la Educación, Humanidades, Artes y Bellas Artes

Año II. Vol II. N³.

Enero - Junio, 2019

Hecho el depósito de Ley: FA2018000022

ISSN: 2665-0282

FUNDACIÓN KOINONIA (F.K).

Santa Ana de Coro, Venezuela

Carely Bello

\section{RESULTADOS}

\section{Cuadro 1}

Comunicación efectiva

Alternativas

Frecuencia

Total \%

Siempre

Casi siempre

3

3

Algunas veces

4

Casi nunca

Nunca

La opción siempre obtuvo un $18 \%$, casi siempre $19 \%$, algunas veces $25 \%$ casi nunca $19 \%$ y nunca $19 \%$, aunado que la sumatoria de las alternativas negativas suman un $63 \%$.

\section{Cuadro 2}

Comunicación efectiva en el gerente educativo

\section{Alternativas}

Siempre

Casi siempre

Algunas veces

Casi nunca
Frecuencia

2

\section{Total \%}

$\begin{array}{ll}2 & 12 \\ 3 & 19\end{array}$


EPISTEME KOINONIA

Revista Electrónica de Ciencias de la Educación, Humanidades, Artes y Bellas Artes

Año II. Vol II. N`3.

Enero - Junio, 2019

Hecho el depósito de Ley: FA2018000022

ISSN: 2665-0282

FUNDACIÓN KOINONIA (F.K).

Santa Ana de Coro, Venezuela

Carely Bello

Nunca

La opción siempre obtuvo un $12 \%$, casi siempre $19 \%$, algunas veces $19 \%$ casi nunca $25 \%$ y nunca $25 \%$, aunado que la sumatoria de las alternativas negativas suman un $69 \%$.

\section{Cuadro 3}

Relaciones interpersonales

Alternativas Frecuencia Total \%

Siempre
Casi siempre

Algunas veces

Casi nunca

Nunca

La opción siempre obtuvo un $19 \%$, casi siempre $25 \%$, algunas veces $25 \%$ casi nunca $12 \%$ y nunca $19 \%$, aunado que la sumatoria de las alternativas negativas suman un $56 \%$.

\section{Cuadro 4}

Toma de decisiones

\begin{tabular}{|c|c|c|}
\hline Alternativas & Frecuencia & Total \% \\
\hline Siempre & 3 & 18 \\
\hline Casi siempre & 3 & 19 \\
\hline
\end{tabular}


EPISTEME KOINONIA

Revista Electrónica de Ciencias de la Educación, Humanidades, Artes y Bellas Artes
Año II. Vol II. N³.
Enero - Junio, 2019
Hecho el depósito de Ley: FA2018000022
ISSN: 2665-0282
FUNDACIÓN KOINONIA (F.K).
Santa Ana de Coro, Venezuela

Carely Bello

Algunas veces

Casi nunca

Nunca

Total 16 100

La opción siempre obtuvo un 18\%, casi siempre 19\%, algunas veces $25 \%$ casi nunca $19 \%$ y nunca $19 \%$, aunado que la sumatoria de las alternativas negativas suman un $63 \%$.

\section{Cuadro 5}

Habilidades comunicativas del gerente educativo

\begin{tabular}{lccc}
\multicolumn{1}{c}{ Alternativas } & Frecuencia & Total \% & 19 \\
Siempre & 3 & 25 \\
Casi siempre & 4 & 31 \\
Algunas veces & 5 & 19 \\
Casi nunca & 3 & 6 \\
Nunca & 1 & 100 \\
& Total & 16 & 19 \\
\hline
\end{tabular}

La opción siempre obtuvo un 19\%, casi siempre 25\%, algunas veces $31 \%$ casi nunca $19 \%$ y nunca $6 \%$, aunado que la sumatoria de las alternativas negativas suman un $56 \%$

\section{DISCUSIÓN}

Los resultados relacionados a la comunicación efectiva, tienden a las alternativas negativas con un $63 \%$, lo cual se contrarresta con la propuesta de Zurita (2018), quien explica que la comunicación es un factor clave para la generación de relaciones efectivas entre los actores educativos con la finalidad de propiciar un clima organización 


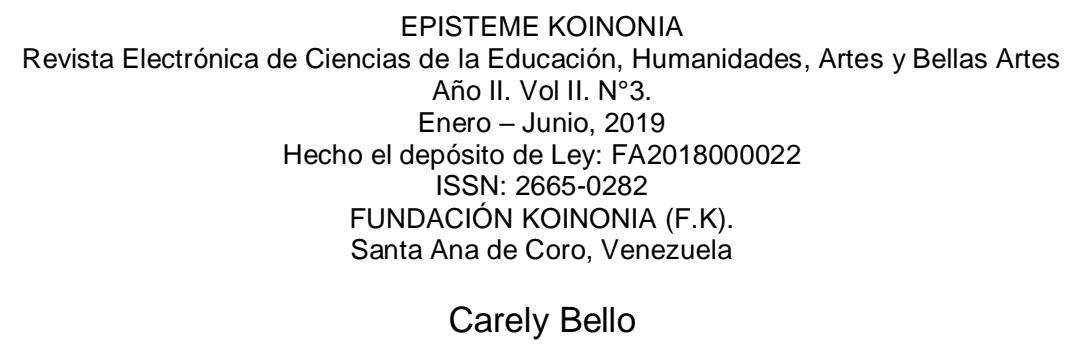

óptimo en función de contar con un trabajo en equipo favorable al logro de los objetivos comunes.

En cuanto a la comunicación efectiva en los gerentes educativos, las alternativas negativas al sumar un $63 \%$, implica que no se está desarrollando adecuadamente la comunicación entre los gerentes y docentes, padres, representantes, lo cual dificulta que la comunidad educativa pueda construir un ambiente de trabajo armónico y efectivo para el logro de metas comunes, siendo esto relacionado con la propuesta de Reyes Aular (2016), quien argumenta la necesidad de promover estrategias de integración entre los miembros de la comunidad educativa con la finalidad de articular la participación protagónica y efectiva en la puesta en marcha de planes institucionales promovidos por la gerencia educativa.

En cuanto a las relaciones interpersonales, las alternativas negativas suman un $56 \%$, implicando que no se está efectuando un adecuado desarrollo de las relaciones comunicativas y sociales entre los miembros de la comunidad educativa, siendo contrastante con la propuesta de Bisquerra (2003), una relación interpersonal "es una interacción recíproca entre dos o más personas" (p. 421), siendo pertinente que la institución educativa promueva la aplicación de acciones que favorezcan la generación de relaciones interpersonales asertivas como medio de crecimiento personal y organizacional.

En cuanto a la toma de decisiones, las alternativas negativas suman un $63 \%$, lo cual contradice a Chiavenato (2004) considera que: "la toma de decisiones es la selección de un curso de acciones entre varias alternativas, y constituye por lo tanto la esencial de la planeación" (p. 157), siendo que no se estarían tomando decisiones apropiadas en conformidad a la planeación estratégica de la institución, siendo pertinente promover un plan de acción donde los actores que conforman la comunidad educativa participen en la elaboración del mismo como parte de promover un adecuado ejercicio democrático de participación institucional. 


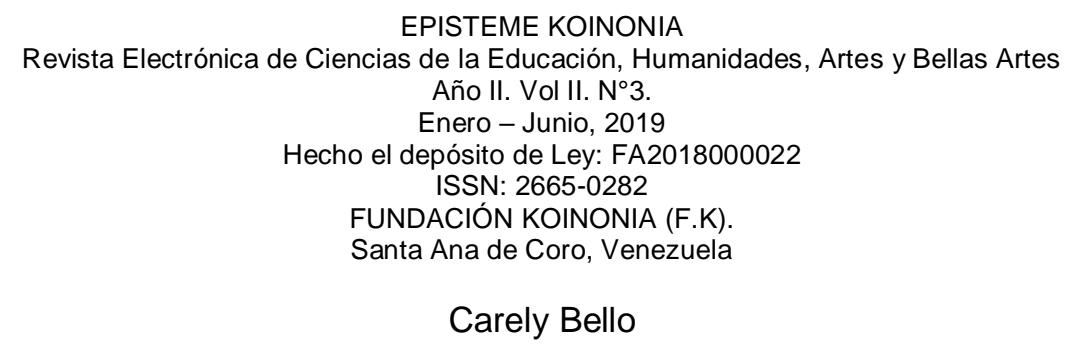

Las habilidades comunicativas del gerente educativo, las alternativas negativas suman un 56\%, ante lo cual, Bateman y Snell (2009) señala que "en la comunicación oral, pueden hacerse y contestarse preguntas, que la retroalimentación en inmediata y directa; de que el receptor puede percibir la sinceridad del emisor, y de que es más persuasiva" (p. 542). El gerente debe trasmitir mensajes claros y precisos para evitar distorsiones en el mensaje y conflictos, el gerente debe tener una escucha, observar al otro, expresar que está escuchando, no distraerse, no interrumpir a quien habla, no juzgar, no ser prematuro al ofrecer ayuda o soluciones, respetar el turno de hablar, con contar argumentos, evitar el síndrome del experto.

\section{CONCLUSIONES}

La comunicación a través del dialogo, implica la respuesta del receptor al emisor de acuerdo al mensaje recibido, entre los principios para que se fundamente efectivamente la retroalimentación constructiva se tiene: se basa en la confianza entre emisor y receptor, es más específica, se suministra en el instante.

El gerente educativo debe tener habilidades para la redacción, buena ortografía, para ello el gerente debe escribir con claridad, respetar al lector, ir al punto, obtener una segunda opinión.

El gerente debe trasmitir mensajes claros y precisos para evitar distorsiones en el mensaje y conflictos. Entre los elementos que interrumpen la comunicación oral se mencionan: sintonía del lenguaje, subjetividad, verborrea, dispersión; ante estas barreras el gerente puede preparar siempre un discurso, tomar en cuenta las características del público, buscar el objetivo al hablar, usar un lenguaje accesible y atractivo, vocalizar correctamente, utilizar apoyos.

La investigación debe ser desarrollada en una segunda fase con la intención de conocer con mayor profundidad las consecuencias que origina la no generación efectiva de la comunicación por parte del gerente educativo. 


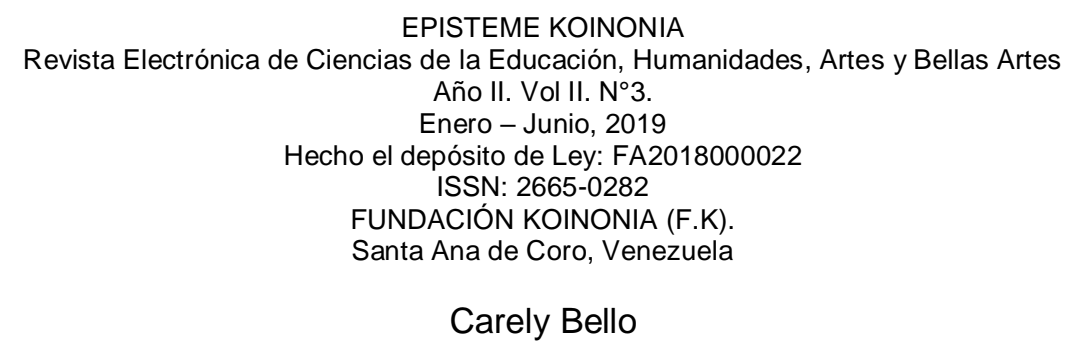

\section{REFERENCIAS}

1. Arias, O. y Heredia, P. (2009). La comunicación. Editorial Kapeluz. Argentina.

2. Bateman T. y Snell, B (2009). Administración, Liderazgo y Colaboración en un Mundo Competitivo. México, Octava Edición. Editorial Mc. Graw Hill.

3. Bisquerra, J. (2003). Relaciones Interpersonales. Editorial: Mac Graw Hill.

4. Cava, L. y Gonzalo, C. (2007) La Comunicación. Madrid: Ediciones Mora.

5. Ceballos, E. (2013). Comunicación Efectiva y su Incidencia en el Clima Organizacional, en la Escuela de Educación Básica. Tesis de Maestría en Gerencia Avanzada en Educación. Dirección de Estudios de Postgrado. Facultad de Ciencias de la Educación. Universidad de Carabobo.

6. Chávez, A. (2010) Metodología de la Investigación. Universidad del Zulia. Maracaibo.

7. Chiavenato, I. (2000) Administración de recursos humanos. Quinta edición. México. Mc Gran. Hill Interamericana.

8. Chiavenato, I. (2004). Gestión del Talento Humano. Cuarta Edición. Bogotá, Editorial McGraw Hill.

9. Daft, R. \& Marcic, D (2010). Introducción a la Administración. (6º Ed.). México Cengage Rearning.

10. Davis, K. \& Newstrom, J. (2003). Comportamiento Humano en el trabajo. 5ta Edición. Editorial Mc. Graw Hill. México.

11. Fernández, J. (2003). Relaciones Interpersonales. Editorial: Mac Graw Hill. México.

12. Hernández, M. (2007). Teorías de las funciones gerenciales. Recuperado a partir de http://www.selorg/cuadernos/articulos/marin.com.

13. Maldonado, R. (2009). Clima laboral y compromiso organizacional de los empleados administrativos de una universidad pública. Trabajo presentado en XV Congreso Internacional de Investigación en Ciencias Administrativas, A.C. (ACACIA). Mayo. México. 


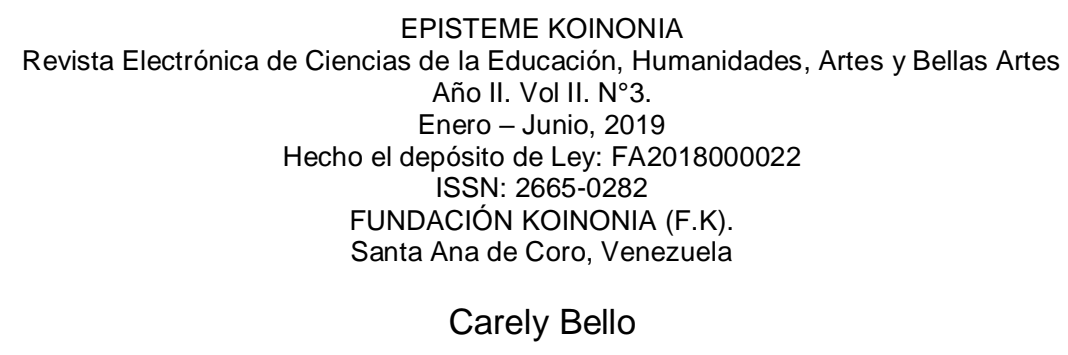

14. Medina, F. (2010) La Integración de las Familias Venezolanas a la Escuela: Un Problema Social. Diario La Mañana. Edición del día 18-11-2010.

15. Morán, F. (2008) Las relaciones interpersonales: Valores y Actitudes. México: Editorial Fondo de Cultura Económica.

16. Munich \& García (1999). Fundamentos de la Administración. Editorial Trillas. Primera Edición. México.

17.Peña. S. (2010). Análisis de la Actuación Gerencial de los directores escolares en 1era y 2 da etapa de educación básica. Maracay. Trabajo de grado no publicado. Universidad Bicentenaria de Aragua.

18. Reyes Aular, M. (2016). Programa de estrategias pedagógicas dirigido a los docentes para la participación de la familia al proceso de aprendizaje en la atención educativa no convencional. Revista Arbitrada Interdisciplinaria Koinonía, 1(2), 50-73. Recuperado de https://fundacionkoinonia.com.ve/ojs/index.php/revistakoinonia/article/view/39/27

19. Robbin, S. (2009). La comunicación en las organizaciones. Caracas-Venezuela .Editorial Futuro.

20. Robbins, S (2004). Comportamiento Organizacional. (4² Ed.) Pearson Educación. México.

21. Robbins, S. (1999). Administración. Teoría y Práctica. 6ta Edición Editorial Prentice Hall Hispanoamérica. México.

22. Robbins, S. \& Coulter, M. (2010). Administración. 10 Edición. México Pearson Educación.

23. UNESCO (2007) Informe para América Latina y El Caribe. Caso Puerto Rico. Bogotá: Ediciones El Cid.

24.Zurita, I. (2018). Gerencia estratégica como herramienta de transformación en la gestión educativa. EPISTEME KOINONIA, 1(2), 35-60. Recuperado de https://fundacionkoinonia.com.ve/ojs/index.php/epistemekoinonia/article/view/510 $\underline{699}$ 
EPISTEME KOINONIA

Revista Electrónica de Ciencias de la Educación, Humanidades, Artes y Bellas Artes

Año II. Vol II. N ${ }^{\circ} 3$.

Enero - Junio, 2019

Hecho el depósito de Ley: FA2018000022

ISSN: 2665-0282

FUNDACIÓN KOINONIA (F.K).

Santa Ana de Coro, Venezuela

\section{Carely Bello}

C2019 por el autor. Este artículo es de acceso abierto y distribuido según los términos y condiciones de la licencia Creative Commons Atribución-NoComercial-Compartirlgual 4.0 Internacional (CC BY-NC-SA 4.0) (https://creativecommons.org/licenses/by-nc-sa/4.0/). 